\title{
A cross-sectional study on factors associated with hypertension and genetic polymorphisms of renin-angiotensin- aldosterone system in Chinese hui pilgrims to hajj
}

Yinxia Zhang ${ }^{1,2}$, Fangfang Shi ${ }^{3}$, Zhanbiao Yu ${ }^{4}$, Aimin Yang ${ }^{5}$, Maolan Zeng ${ }^{2}$, Jiaoyue Wang ${ }^{6}$, Haiping Yin ${ }^{6}$, Benzhong Zhang ${ }^{7}$ and Xiao $\mathrm{Ma}^{1 *}$ (D)

\begin{abstract}
Background: Hypertension is the leading risk factor for cardiovascular disease (CVD), however, the studies on lifestyle and genetic risks in Chinese pilgrims to Hajj was limited. The aim of this study is to examine the prevalence and associated lifestyle and genetic risks for hypertension among Hui Hajj pilgrims in China.

Methods: We performed a cross-sectional analysis of data in 1,465 participants aged 30-70 years who participated in a medical examination for Hui Hajj pilgrims from Gansu province, China in 2017. Multiple logistic regression was used to evaluate the association of potential risk factors with hypertension. Deoxyribonucleic acid (DNA) polymorphism was examined at sites in the renin-angiotensin-aldosterone system (RAAS).

Results: The prevalence of hypertension was $47 \%$ among this population. Lifestyle factors such as fried food preference (like vs. dislike: odds ratio [OR]: $=1.53,95 \%$ confidence interval [Cl]: 1.13-2.09) and barbecued food preference (like vs. dislike: $\mathrm{OR}=1.45,95 \% \mathrm{Cl}: 1.06-1.97$ ) were associated with elevated risk of hypertension among Hui pilgrims. Comparing with Angiotensin converting enzyme (ACE) rs4425 AA genotype, $\pi$ genotype was associated with hypertension risk $(\mathrm{OR}=2.16,95 \% \mathrm{Cl}: 1.17-4.00)$. Similar results were also observed for $A C E$ rs4437 CC genotype (OR $=1.95,95 \%$ Cl: $1.07-$ 3.55), Angiotensin II receptor (ATR) rs129876 AA genotype (OR $=4.10,95 \% \mathrm{Cl}: 2.30-7.32)$ and Aldosterone synthase (CYP11B2) rs $1912 \pi$ genotype (OR $=2.82,95 \%$ Cl: 1.57-5.06) genotypes.
\end{abstract}

Conclusions: Unhealthy lifestyle and genetic factors were associated with the prevalence of hypertension in Chinese Hui pilgrims and their interactions were also observed.

Keywords: Pilgrims, Hypertension, RAAS, Polymorphism

\section{Background}

Hypertension is an important risk factor of morbidity and mortality related to cardiovascular diseases, stroke and other diseases, which is related to both genetic and environmental factors [1]; The effects of hypertension on the body are slow-acting, heterogeneous, and varying among different ethnic groups [2, 3], particularly for

\footnotetext{
*Correspondence: antiaids@163.com

'West China School of Public Health and West China Fourth Hospital,

Sichuan University, Chengdu 610000, China

Full list of author information is available at the end of the article
}

those who are 65 years and older [4]. According to data from the World Health Organization, more than 1.5 billion people globally will have hypertension by 2025 [5]. Once in a lifetime every Muslim is expected to undergo a holy pilgrimage, known as Hajj, which takes place in the 12th month of the Islamic lunar calendar. Every year an estimated two million Muslim pilgrims gather from all around the world to perform the holy pilgrimage. Over the past few years cardiovascular diseases have emerged as an important cause both of intensive care unit (ICU) admission and of mortality during Hajj [6].

(c) The Author(s). 2019 Open Access This article is distributed under the terms of the Creative Commons Attribution 4.0 International License (http://creativecommons.org/licenses/by/4.0/), which permits unrestricted use, distribution, and reproduction in any medium, provided you give appropriate credit to the original author(s) and the source, provide a link to the Creative Commons license, and indicate if changes were made. The Creative Commons Public Domain Dedication waiver (http://creativecommons.org/publicdomain/zero/1.0/) applies to the data made available in this article, unless otherwise stated. 
The burden of hypertension and its complications are substantial among Muslims from all over the world who make the Hajj pilgrimage to Mecca, Saudi Arabia [7, 8]. However, few studies have addressed the risk factors of hypertension on Muslim pilgrims till now.

More than 150 genes have been linked to hypertension and genetic risk factors appear to vary with time and study population $[9,10]$, the genes encoding the proteins involved in the renin-angiotensin-aldosterone system $(R A A S)$ consistently appear to be key factors in hypertension. Blood pressure rises when renin and angiotensinconverting enzyme $(A C E)$ convert angiotensinogen (AGT) into angiotensin I (Ang I) and angiotensin ll (Ang II). Then Ang II combines with its cognate receptor (angiotensin II receptor, $A T R)[1,11,12]$. Blood pressure is also directly regulated by aldosterone, which is produced by aldosterone synthase (CYP11B2)[13]. The susceptibility of these genes may play fundamental roles in the development of hypertension and therefore become the focus of our study.

In addition to genetic risk factors, lifestyle and behavioral factors also contribute to essential hypertension. These factors included over weight and obesity, alcohol drinking, tobacco smoking, physical inactivity, unhealthy dietary habits (adequate consumption of fruits and vegetables), having diabetes, elevated non-HDL cholesterol, and chronic kidney disease [14-16]. Though Muslims adhere to Islam's prohibition against alcohol and smoking, [17] reports of Gansu Muslims who have made the Hajj pilgrimage indicated high prevalence of hypertension of $60.69 \%$ in 2013 [18] and always higher than the national average according to the Gansu International Travel Healthcare Center statistics. Few studies have addressed on Hajj pilgrims that are special ethnic group in China.

With the aim of understanding what genetic and lifestyle factors are responsible for the increased risk of hypertension among Hui Hajj pilgrims in China, we examined the hypertension prevalence and factors associated with hypertension as well as explored polymorphism in RAAS genes and lifestyle factors in Hui Hajj pilgrims.

\section{Methods}

\section{Participants}

We conducted a cross-sectional analysis based on data obtained from the medical examination for Hajj pilgrims from Gansu, China in 2017. We choose the entire participants who completed the medical examination for Hajj pilgrims. A total of 1,465 Hui pilgrims including 833 men and 632 women were contained with the mean age of $57.0 \pm 9.4$ years. All participants completed a demographic characteristic-related questionnaire, physical examination, and clinical tests, and participated in the Hajj pilgrimage to Mecca in 2017. Individuals were interviewed and subjected to a physical examination. Their blood samples were also collected in order to further conduct genetic testing and analysis. The study protocol was approved by the Medical Research Ethics Committee of the Northwestern University for Nationalities, and all participants provided written informed consent before enrollment.

\section{Data collection}

Several types of data were collected in this study including questionnaire data obtained from in-person interviews, clinical data from physical examination and laboratory tests, and biospecimen collection. In-person interviews were conducted by trained interviewers using a standardized and structured questionnaire. The interviewers were trained to administer the questionnaire in a standardized fashion. Demographic information included age, sex, marital status, education, occupation, consumption of alcohol, use of tobacco, family history of hypertension, and dietary habits. Clinical data were obtained from physical examination and laboratory tests. According to the results of physical examination and the diagnostic criteria for hypertension, the subjects were divided into normal blood pressure group and hypertension group according to blood pressure values. The 200 biological samples were randomly selected from the each groups separately subjects for genetic polymorphism detection of RAAS system. A total of 357 qualified serum samples was included for DNA extraction, including 195 and 162 participants without and hypertension.

\section{Physical examination}

The examination included a measurement of weight, height and blood pressure. Automatical recording instruments (DHM-301, DINGHENG, China) were used to measure weight and height. Body mass index (BMI) was calculated as weight in kilograms divided by the square of height in meters. Systolic blood pressure (SBP) and diastolic blood pressure (DBP) were measured by a well-trained physician, which was measured after the participants had been seated for 5-min. Individuals underwent three readings of arterial pressures in a seated position using an automatic pulse sphygmomanometer [19](UDEX-TWIN, Japan). Those with average systolic blood pressure $\geq 160 \mathrm{mmHg}$ were re-measured three times the next morning. Laboratory tests included blood samples from all participants under fasting conditions in the morning at the International Health Center for Entry-Exit Health in Gansu Province. Routine laboratory tests were conducted including blood tests (Xeitomex XT-1800 Analyzer), blood biochemistry (Kerman Coulter AU680 Biochemistry Analyzer), electrocardiography (Japan Photoelectric ECG-9130P), and chest X-ray (DRX-1). 
Table 1 Characteristics of Chinese pilgrims to Hajj by hypertension $(n=1465)$

\begin{tabular}{|c|c|c|c|c|}
\hline \multirow[t]{2}{*}{ Characteristic } & \multicolumn{3}{|l|}{ Hypertension } & \multirow[t]{2}{*}{$P$ value } \\
\hline & Normal & Cases & Overall & \\
\hline Number of participants & $777(53.0)$ & $688(47.0)$ & $1465(100)$ & \\
\hline Age (years) & $54.5 \pm 9.2$ & $59.8 \pm 8.8$ & $57 \pm 9.4$ & $<0.01$ \\
\hline$\leq 40$ & $43(5.5)$ & $10(1.5)$ & $53(3.6)$ & $<0.01$ \\
\hline $41-50$ & $226(29.1)$ & 95 (13.8) & $321(21.9)$ & \\
\hline $51-60$ & $311(40.0)$ & 247 (35.9) & $558(38.1)$ & \\
\hline$>60$ & $197(25.4)$ & $336(48.8)$ & $533(36.4)$ & \\
\hline \multicolumn{5}{|l|}{ Sex } \\
\hline Male & $425(54.7)$ & $408(59.3)$ & $833(56.9)$ & \multirow[t]{2}{*}{0.08} \\
\hline Female & $352(45.3)$ & $280(40.7)$ & $632(43.1)$ & \\
\hline \multicolumn{4}{|l|}{ Marital status ${ }^{t}$} & \multirow[t]{3}{*}{0.56} \\
\hline Married & 774 (99.6) & $686(99.7)$ & $1460(99.7)$ & \\
\hline Others & $3(0.4)$ & $2(0.3)$ & $5(0.3)$ & \\
\hline \multicolumn{5}{|l|}{ Education (years) } \\
\hline$\leq 6$ & $339(43.6)$ & $336(48.8)$ & $675(46.1)$ & \multirow[t]{4}{*}{0.10} \\
\hline $7-9$ & $256(32.9)$ & $198(28.8)$ & $454(31)$ & \\
\hline $10-12$ & $110(14.2)$ & $82(11.9)$ & $192(13.1)$ & \\
\hline$>12$ & $72(9.3)$ & $72(10.5)$ & $144(9.8)$ & \\
\hline \multicolumn{5}{|l|}{ Occupation } \\
\hline Officer/technician & $60(7.7)$ & 79 (11.5) & $139(9.5)$ & \multirow[t]{4}{*}{$<0.01$} \\
\hline Tradesman & $120(15.4)$ & $63(9.2)$ & $183(12.5)$ & \\
\hline Farmer & $405(52.1)$ & $353(51.3)$ & $758(51.7)$ & \\
\hline Others & $192(24.7)$ & $193(28.1)$ & $385(26.3)$ & \\
\hline \multicolumn{5}{|c|}{ Family income per month (CNY) } \\
\hline$<2500$ & $267(34.4)$ & $257(37.4)$ & $524(35.8)$ & \multirow[t]{4}{*}{0.15} \\
\hline $2500-3499$ & $168(21.6)$ & $147(21.4)$ & $315(21.5)$ & \\
\hline $3500-4500$ & $68(8.8)$ & $75(10.9)$ & $143(9.8)$ & \\
\hline$>4500$ & $274(35.3)$ & $209(30.4)$ & $483(33.0)$ & \\
\hline Height (cm) & $162.5 \pm 7.9$ & $162.2 \pm 8$ & $162.4 \pm 7.9$ & 0.45 \\
\hline Weight (kg) & $67.3 \pm 11.3$ & $69 \pm 11.4$ & $68.1 \pm 11.4$ & $<0.01$ \\
\hline SBP $(m m H g)$ & $126.6 \pm 10.2$ & $150.3 \pm 8.9$ & $137.7 \pm 15.2$ & $<0.01$ \\
\hline $\mathrm{DBP}(\mathrm{mmHg})$ & $73.3 \pm 13.3$ & $79.4 \pm 18.9$ & $76.2 \pm 16.4$ & $<0.01$ \\
\hline $\mathrm{FPG}(\mathrm{mmol} / \mathrm{L})$ & $6.8 \pm 1.4$ & $7.2 \pm 1.6$ & $7 \pm 1.5$ & $<0.01$ \\
\hline BMI $\left(\mathrm{kg} / \mathrm{m}^{2}\right)$ & $25.4 \pm 3.4$ & $26.1 \pm 3.3$ & $25.8 \pm 3.4$ & $<0.01$ \\
\hline Underweight $(<18.5)$ & $11(1.4)$ & $4(0.6)$ & $15(1)$ & \multirow[t]{4}{*}{$<0.01$} \\
\hline Normal (18.5-24.99) & $345(44.4)$ & $250(36.3)$ & $595(40.6)$ & \\
\hline Overweight (25-29.9) & $353(45.4)$ & $356(51.7)$ & $709(48.4)$ & \\
\hline Obese $(\geq 30)$ & $68(8.8)$ & $78(11.3)$ & $146(10.0)$ & \\
\hline Tobacco smoking & $55(7.1)$ & $53(7.7)$ & $108(7.4)$ & 0.65 \\
\hline Alcohol drinking & $32(4.1)$ & $28(4.1)$ & $60(4.1)$ & 0.96 \\
\hline \multicolumn{5}{|l|}{ Fried food preference } \\
\hline Dislike & $230(29.6)$ & $210(30.5)$ & $440(30)$ & \multirow[t]{3}{*}{0.75} \\
\hline Neither like nor dislike & $175(22.5)$ & $162(23.5)$ & $337(23)$ & \\
\hline Like & $372(47.9)$ & $316(45.9)$ & $688(47)$ & \\
\hline
\end{tabular}


Table 1 Characteristics of Chinese pilgrims to Hajj by hypertension ( $n=1465)$ (Continued)

\begin{tabular}{|c|c|c|c|c|}
\hline \multirow[t]{2}{*}{ Characteristic } & \multicolumn{3}{|c|}{ Hypertension } & \multirow[t]{2}{*}{$P$ value } \\
\hline & Normal & Cases & Overall & \\
\hline \multicolumn{5}{|l|}{ Barbecued food preference } \\
\hline Dislike & $331(42.6)$ & $279(40.6)$ & $610(41.6)$ & \multirow[t]{3}{*}{0.12} \\
\hline Neither like nor dislike & $224(28.8)$ & $179(26)$ & $403(27.5)$ & \\
\hline Like & $222(28.6)$ & $230(33.4)$ & $452(30.9)$ & \\
\hline \multicolumn{5}{|l|}{ Worship frequency (days/week) } \\
\hline$<3$ & $174(22.4)$ & $133(19.3)$ & $307(21.0)$ & \multirow[t]{3}{*}{0.34} \\
\hline $3-5$ & $179(23)$ & $169(24.6)$ & $348(23.8)$ & \\
\hline$>5$ & $424(54.6)$ & $386(56.1)$ & $810(55.3)$ & \\
\hline Diabetes & $260(33.5)$ & $312(45.3)$ & $572(39.0)$ & $<0.01$ \\
\hline Family history of hypertension & $37(4.8)$ & $35(5.1)$ & $72(4.9)$ & 0.77 \\
\hline
\end{tabular}

\section{Definitions}

Based on diagnostic criteria of the World Health Organization and the International Society of Hypertension, hypertension was defined as systolic blood pressure $\geq 140 \mathrm{mmHg}$ or diastolic blood pressure $\geq 90 \mathrm{mmHg}$ or using anti-hypertensive therapies [20]. Diabetes was defined as fasting plasma glucose $\geq 126 \mathrm{mg} /$ $\mathrm{dL}(\geq 7.0 \mathrm{mmol} / \mathrm{L})$ or use of anti-diabetic medication at the time of the baseline interview (ADA, 2014). Tobacco smoking was defined as those who smoked at least one cigarette per day in the past 6 months. Alcohol drinking was defined as those who drank hard liquor, beer, or wine at least one time per week in the past 6 months. Family history of hypertension was based on participants reporting as having at least one parent, sibling, or offspring with hypertension.

\section{Genotyping of RAAS polymorphism}

Genomic Deoxyribonucleic acid (DNA) was extracted from blood using a commercial kit (Omega Bio-Tek, D6919-01B). DNA concentrations were determined on a $1 \%$ agarose gel imaging system (Bio-RAD, USA) and a UV spectrophotometer (Pultton P200, USA). Samples $(20 \mu \mathrm{L})$ were randomly selected from the qualified DNA extracts and diluted to $18-22 \mathrm{ng} / \mu \mathrm{L}$ for PCR amplification. The remaining samples were stored at $-80^{\circ} \mathrm{C}$ for later use.

Polymerase Chain Reaction (PCR) was carried out to amplify regions within the coding sequences of the genes for AGT (accession: chromosome 1, NC_000001.11, gene ID: 183), $A C E$ (chromosome 17, NC_000017.11, gene ID: 1636), ATR (chromosome 3, NC_000003.12, gene ID: 545), and CYP11B2 (chromosome 8, NC_000008.11, gene ID: 1585). PCR primers were designed using Primer Premier 5.0 and Oligo 7 (Additional file 1: Table S1), then synthesized by Shanghai Biological Engineering (Shanghai, China). PCR reactions $(25 \mu \mathrm{L})$ contained $1 \mu \mathrm{L}$ of genomic DNA $(18-22 \mathrm{ng} / \mu \mathrm{L}), 1 \mu \mathrm{L}$ each of upstream and downstream primers $(10 \mathrm{pmol} / \mu \mathrm{L}), 12.5 \mu \mathrm{L}$ of $2 \mathrm{X}$ Taq PCR Master Mix (containing Taq DNA polymerase $\mathrm{Mg}^{2+} \cdot \mathrm{dNTPs}$ ), and $9.5 \mu \mathrm{L}$ of sterilized ultrapure water.

PCR products were checked by agarose gel electrophoresis, then sent for sequencing to the Suzhou Jinweizhi Biological Technology Co., Ltd. Sequencing results were analyzed using DNAstar and DNAMAN software.

Finally, genotypes at polymorphic sites in $R A A S$ genes were analyzed using high-resolution melting analysis. Primers were designed using Light Scanner software (Additional file 1: Table S2). To ensure accurate genotyping, the primers were tested on samples previously collected from individuals similar to the study population $[21,22]$. In addition, melting curves were calibrated using high- and low-temperature internal standard (Additional file 1: Table S3) [23].

PCR reactions for high-resolution melting $(11 \mu \mathrm{L})$ contained $1 \mu \mathrm{L}$ of genomic DNA $(18-22 \mathrm{ng} / \mu \mathrm{L}), 1 \mu \mathrm{L}$ each of upstream and downstream primers $(10 \mathrm{pmol} / \mu \mathrm{L}), 5 \mu \mathrm{L}$ of 2X Taq PCR Master Mix (BioTeke, Beijing, China), $1 \mu \mathrm{L}$ of LC Green saturated dye (Idaho Technology, USA) and $2 \mu \mathrm{L}$ of ultrapure water. Reaction conditions were as follows: initial denaturation at $95^{\circ} \mathrm{C}$ for $5 \mathrm{~min}$; 35 cycles of initial denaturation at $94{ }^{\circ} \mathrm{C}$ for $20 \mathrm{~s}$, renaturation for $20 \mathrm{~s}$ at the appropriate annealing temperature, and extension at $72{ }^{\circ} \mathrm{C}$ for $20 \mathrm{~s}$; a final extension at $72{ }^{\circ} \mathrm{C}$ for $10 \mathrm{~min}$; and storage at $4{ }^{\circ} \mathrm{C}$. Then $1 \mu \mathrm{L}$ each of the diluted high- and lowtemperature internal standards were added to the reaction wells and incubated in a $95^{\circ} \mathrm{C}$ water bath for $30 \mathrm{~s}$, followed by incubation in a $25^{\circ} \mathrm{C}$ water bath for $30 \mathrm{~s}$. Signals were analyzed using a Light Scanner 96 high-resolution melting curve analysis system (Idaho Technology, USA).

\section{Statistical analysis}

Descriptive statistics of continuous variables were obtained by calculating mean value and standard deviation 


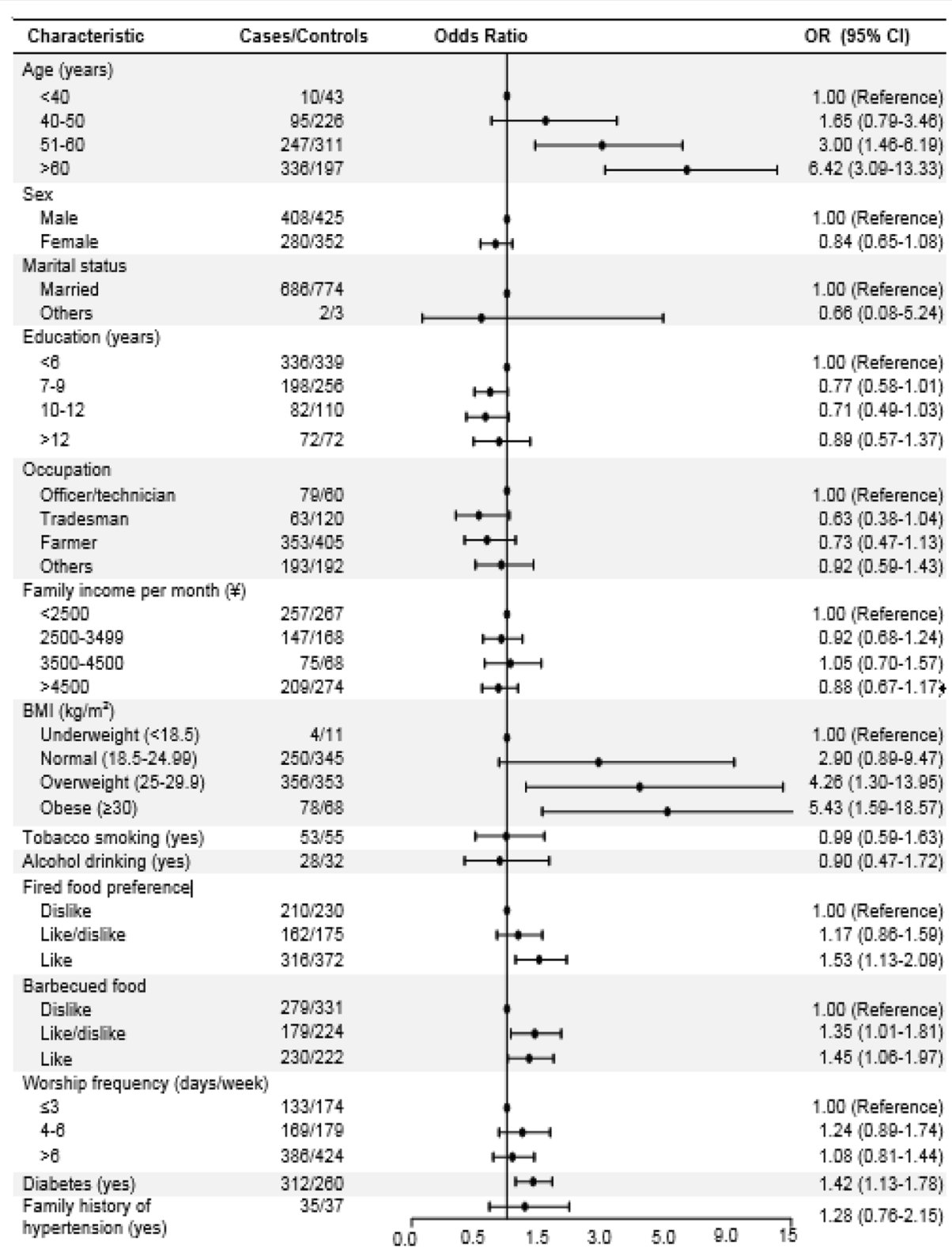

Fig. 1 Associations between basic characteristics and hypertension risk in Hui pilgrims to Hajj. The dots and horizontal lines are ORs and 95\% confidence intervals (Cls) using logistic regression analysis

(SD), and categorical variables were obtained by calculating the number and frequency distribution. $T$ test or Chi-square test were used to detect the differences among participants' characteristics. Furthermore, multiple logistic regression models were used to evaluate the association between hypertension and risk factors. Age were categorized into equally spaced categories: $\leq 40$ years, $41-50$ years, $51-60$ years, and $>60$ years. Years of education were categorized into meaningful spaced categories: $\leq 6$ years (primary school), 7-9 years (middle school), 10-12 years (high school), > 12 years (college or above). Consistency of polymorphic genotypes with the predictions of Hardy-Weinberg equilibrium was tested using SHESIS software. Genotype frequencies were compared between hypertension and normal groups. All analyses were performed using IBM SPSS 20.0 Software (IBM, Chicago, IL, USA).

\section{Results}

Basic characteristics

The mean age of participants was $57 \pm 9.4$ years $(57.7 \pm$ 9.5 years for men, women: $56.1 \pm 9.2$ years for women), and the average BMI was $25.8 \pm 3.4 \mathrm{~kg} / \mathrm{m}^{2} .56 .9 \%$ of the participants were male, and $46.1 \%$ of them were illiteracy. 
Table 2 Comparison of Characteristics between Participants with and without Genetic Tests

\begin{tabular}{|c|c|c|c|}
\hline \multirow[t]{2}{*}{ Characteristic } & \multicolumn{2}{|l|}{ Participants } & \multirow[t]{2}{*}{$P$ value } \\
\hline & $\begin{array}{l}\text { Without Gene } \\
\text { Tests }\end{array}$ & $\begin{array}{l}\text { With Gene } \\
\text { Tests }\end{array}$ & \\
\hline Number of participants & $1108(75.6)$ & $357(24.4)$ & \\
\hline \multicolumn{4}{|l|}{ Age (years) } \\
\hline$<40$ & $40(3.6)$ & $13(3.6)$ & \multirow[t]{4}{*}{0.50} \\
\hline $40-50$ & $240(21.7)$ & $81(22.7)$ & \\
\hline $51-60$ & $434(39.2)$ & $124(34.7)$ & \\
\hline$>60$ & 394 (35.6) & 139 (38.9) & \\
\hline \multicolumn{4}{|l|}{ Sex } \\
\hline Male & $629(56.8)$ & $204(57.1)$ & \multirow[t]{2}{*}{0.90} \\
\hline Female & $479(43.2)$ & $153(42.9)$ & \\
\hline \multicolumn{4}{|l|}{ Marital status } \\
\hline Married & 1104 (99.6) & $356(99.7)$ & \multirow[t]{2}{*}{0.82} \\
\hline Others & $4(0.4)$ & $1(0.3)$ & \\
\hline \multicolumn{4}{|c|}{ Family income per month ( $¥)$} \\
\hline$<2500$ & $411(37.1)$ & $113(31.7)$ & \multirow[t]{4}{*}{0.06} \\
\hline $2500-3499$ & $245(22.1)$ & 70 (19.6) & \\
\hline $3500-4500$ & $100(9.0)$ & $43(12.0)$ & \\
\hline$>4500$ & $352(31.8)$ & $131(36.7)$ & \\
\hline \multicolumn{4}{|l|}{ BMI (kg/m2) } \\
\hline Underweight $(<18.5)$ & $11(1.0)$ & $4(1.1)$ & \multirow[t]{4}{*}{0.31} \\
\hline Normal (18.5-24.99) & $435(39.3)$ & $160(44.8)$ & \\
\hline $\begin{array}{l}\text { Overweight (25- } \\
\text { 29.9) }\end{array}$ & $549(49.5)$ & $160(44.8)$ & \\
\hline Obese $(\geq 30)$ & $113(10.2)$ & $33(9.2)$ & \\
\hline \multicolumn{4}{|l|}{ Tobacco smoking } \\
\hline Yes & $77(6.9)$ & $31(8.7)$ & \multirow[t]{2}{*}{0.28} \\
\hline No & $1031(93.1)$ & $326(91.3)$ & \\
\hline \multicolumn{4}{|l|}{ Alcohol drinking } \\
\hline Yes & $43(3.9)$ & $17(4.8)$ & \multirow[t]{2}{*}{0.47} \\
\hline No & $1065(96.1)$ & $340(95.2)$ & \\
\hline \multicolumn{4}{|c|}{ Worship frequency (days/week) } \\
\hline$<3$ & $240(21.7)$ & $67(18.8)$ & \multirow[t]{3}{*}{0.10} \\
\hline $3-5$ & $273(24.6)$ & $75(21.0)$ & \\
\hline$>5$ & $595(53.7)$ & $215(60.2)$ & \\
\hline \multicolumn{4}{|l|}{ Diabetes } \\
\hline Yes & $438(39.5)$ & $134(37.5)$ & \multirow[t]{2}{*}{0.50} \\
\hline No & $670(60.5)$ & $223(62.5)$ & \\
\hline \multicolumn{4}{|c|}{ Family history of hypertension } \\
\hline Yes & $48(4.3)$ & $24(6.7)$ & \multirow[t]{2}{*}{0.07} \\
\hline No & 1060 (95.7) & 333 (93.3) & \\
\hline
\end{tabular}

Note. ${ }^{*}$ The results from the Chi Square Test
Most of the participants never smoked (92.6\%) nor drank (95.9\%) in their lifetime. The prevalence of hypertension was $47 \%$ among this population. The basic characteristics of participants overall and according to hypertension in those Chinese Hui pilgrims to Hajj were summarized in Table 1. Compared to participants without hypertension, those with hypertension were older, officer/technician, diabetics, and tended to have higher weight, Body mass index (BMI) and Fasting plasma glucose (FPG).

\section{Lifestyle risk factors and hypertension risk}

Figure 1 showed the associations of lifestyle risk factors with hypertension risk among Hui pilgrims to Hajj. Age, BMI, barbecued food preference, fried food preference, and diabetes were significantly associated with higher odds of hypertension after adjusting for multiple confounding factors. Participants who like fried food had $53 \%$ increased risk of hypertension compared with those dislike fried food (odds ration [OR]: 1.53, 95\% confidence interval $[\mathrm{CI}]: 1.13-2.09)$. Compared to those with disfavor barbecued food, those with barbecued food preference were significantly associated with hypertension risk (OR: 1.45, 95\% CI: 1.06-1.97).

\section{Genetic risk factors and hypertension risk}

To further explore the role of genetic risk factors in the development of hypertension among Chinese pilgrims to Hajj, 357 qualified blood samples were randomly selected to conduct genetic testing. We controlled some of the factors for controlling major potential confounders. Table 2 presented the comparison of basic characteristics between participants with and without genetic tests. The result showed that there are no differences in participant's characteristic between the two groups. For example, the percentage of overweight among participants with and without genetic tests was 44.8 and $49.5 \%$, respectively $(P=0.31)$.

Polymorphism was investigated within the coding sequences of four RAAS genes: at three sites within the $A C E$ gene [rs4425 $(A / T)$, rs4429 $(G / A)$ and rs4337 (G/ $C)$ ] (Fig. 2a), as well as at one site each within the $A G T$ gene $[\mathrm{rs} 3637(T / C)], A T R$ gene $[\mathrm{rs} 129876(G / A)]$ and CYP11B2 gene [rs1912 (C/T)] (Fig. 2b). High-resolution melting analysis detected three genotypes at each of the six polymorphic sites. The dominant genotypes at sites in the $A C E$ gene were $A A, G G$, and $C C$ (Fig. 2c). The dominant genotypes were $T T$ at the site in the $A G T$ gene; $G G$ at the site in the ATR gene; and $T T$ at the site in the CYP11B2 gene (Fig. 2d).

Table 3 showed the genotype at polymorphic RAAS sites among participants with and without hypertension. The difference of genotype frequencies among hypertension and normal groups were statistically significantat loci rs4425 $(A / T)$ and rs4337 $(G / C)$ in the $A C E$ gene, at locus rs129876 $(G / A)$ in the $A T R$ gene and at locus 

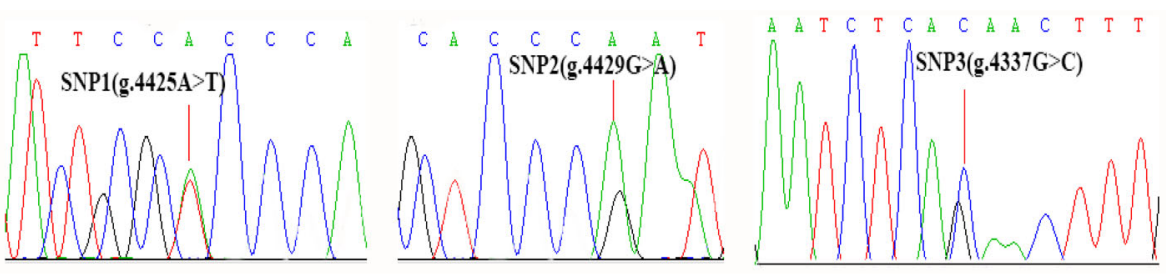

(a) Sequencing of the peak at three loci of $A C E$ gene

The "SNP1", "SNP2" and "SNP3" represent rs4425(A/T), rs4429(G/A) and rs4337(G/C) of $A C E$ gene.

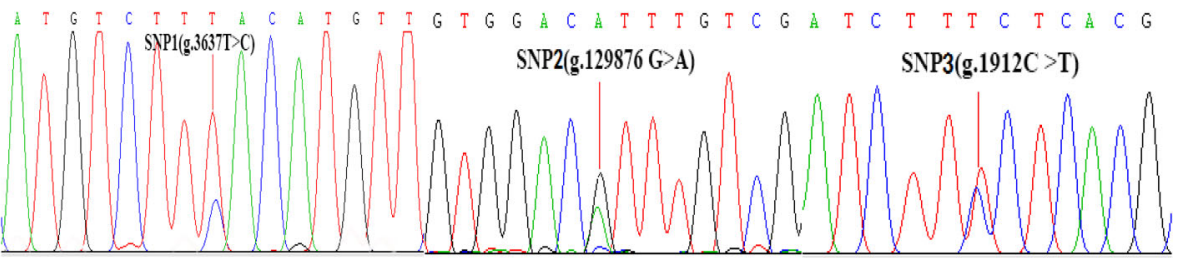

(b) Sequencing of the peak loci of $A G T, A T R$ and CYP11B2 gene

The "SNP1"represent rs3637(T/C) of AGT gene; "SNP2" represent rs129876(G/A) of ATR gene; "SNP3" represent rs1912(C/T) of CYP11B2 gene.
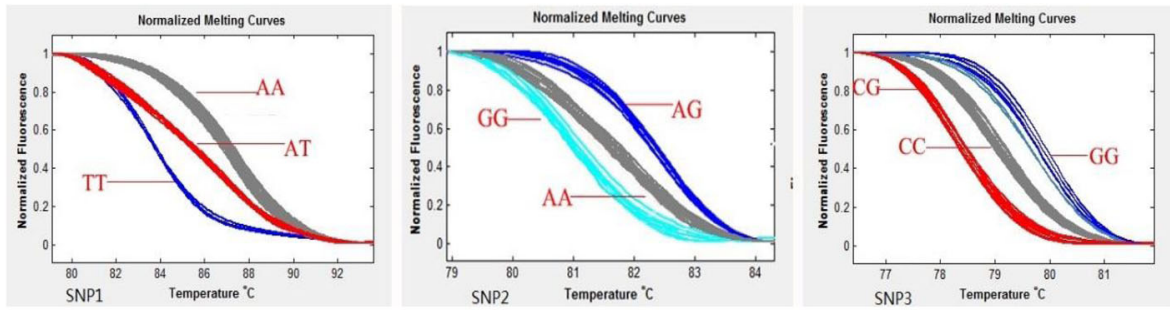

(c) HRM genotype of $A C E$ gene

The "SNP1", "SNP2" and "SNP3" represent rs4425(A/T), rs4429(G/A) and rs4337(G/C) of $A C E$ gene.
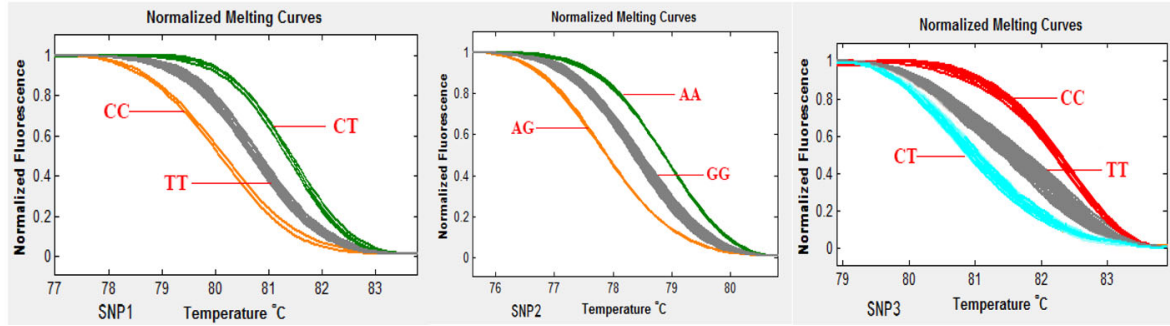

(d) HRM genotype of $A G T, A T R$ and CYP11B2 gene

The "SNP1"represent rs3637(T/C) of AGT gene; "SNP2" represent rs129876(G/A) of ATR gene; "SNP3" represent rs1912(C/T) of CYP11B2 gene.

Fig. 2 The polymorphic loci of tested genes in the studied Hui Pilgrims to Hajj

rs1912 $(C / T)$ in the CYP11B2 gene. Table 4 showed the homozygosity (Ho), heterozygosity (He), effective number of alleles $(\mathrm{Ne})$ and polymorphism information content (PIC). PIC varied from 0.331 to 0.389 corresponding to moderate polymorphism (defined as $0.25<\mathrm{PIC}<0.5$ ). All the sites were consistent with Hardy-Weinberg equilibrium and were representative of the population based on the chisquared test $(P>0.05)$. Figure 3 shows the results of Linkage disequilibrium calculation for ACE polymorphisms.

Figure 4 showed the results of multiple logistic regression models for the association between genotypes and hypertension risk in Chinese pilgrims to Hajj. After adjusting for traditional risk factors, including age, sex, marital status, monthly family income, BMI, tobacco smoking, alcohol drinking, physical activity, diabetes and family history of hypertension, rs4425 TT genotype was associated with the risk of hypertension with an adjusted OR of 2.16 (95\% CI: 1.17-4.00), comparing with $A A$ genotype. rs4337 CC genotype was associated with the risk of hypertension with an adjusted OR of 2.16 (95\% CI: 1.0733.554), comparing with GG genotype. Similar results were also observed for ATR and CYP11B2 genotypes: compared 
Table 3 Genotype and allele frequencies at polymorphic RAAS sites

\begin{tabular}{|c|c|c|c|c|c|c|}
\hline \multirow[t]{2}{*}{ Gene } & \multirow[t]{2}{*}{ Locus } & \multirow[t]{2}{*}{ Group } & \multicolumn{3}{|c|}{ Genotype frequency } & \multirow[t]{2}{*}{$P$ value } \\
\hline & & & $\mathrm{AA}$ & AT & $\pi$ & \\
\hline \multirow[t]{3}{*}{ ACE } & rs4425 & Normal & $81(41.5)$ & $80(41.3)$ & $34(17.4)$ & $<0.01$ \\
\hline & & Cases & $68(42.0)$ & $38(23.4)$ & $56(34.6)$ & \\
\hline & & & GG & $A G$ & AA & \\
\hline \multirow[t]{2}{*}{ ACE } & rs4429 & Normal & $78(40.0)$ & $64(32.8)$ & $53(27.2)$ & 0.42 \\
\hline & & Cases & 76 (46.9) & $47(29.0)$ & $39(24.1)$ & \\
\hline \multirow[t]{4}{*}{ ACE } & rs4337 & & GG & CG & CC & \\
\hline & & Normal & $81(41.5)$ & $71(36.4)$ & $43(22.1)$ & 0.01 \\
\hline & & Cases & $49(30.2)$ & $54(33.3)$ & $59(36.5)$ & \\
\hline & & & GG & $A G$ & $\mathrm{AA}$ & \\
\hline \multirow[t]{3}{*}{ ATR } & rs129876 & Normal & $135(69.2)$ & $28(14.4)$ & $32(16.4)$ & $<0.01$ \\
\hline & & Cases & 69 (42.6) & $29(17.9)$ & 64 (39.6) & \\
\hline & & & $\pi$ & CT & CC & \\
\hline \multirow[t]{3}{*}{ AGT } & rs3637 & Normal & $88(45.1)$ & $39(20.0)$ & $68(34.9)$ & 0.28 \\
\hline & & Cases & 79 (48.7) & $22(13.6)$ & $61(37.7)$ & \\
\hline & & & $\mathrm{CC}$ & CT & $\pi$ & \\
\hline \multirow[t]{2}{*}{ CYP11B2 } & rs1912 & Normal & $67(34.4)$ & $31(15.9)$ & $97(49.7)$ & $<0.01$ \\
\hline & & Cases & $30(18.5)$ & $32(19.8)$ & $100(61.7)$ & \\
\hline
\end{tabular}

Note. ${ }^{*}$ The results from the Chi Square Test

with ATR rs129876 GG genotype, the OR of hypertension risk was 4.10 (95\% CI: 2.30-7.32) for $A A$ genotype. Compared with CYP11B2 rs1912 CC genotype, the OR of hypertension risk was 2.82 (95\% CI: 1,57-5.06) for TT genotype.

\section{Discussion}

This study provides evidence that age, BMI, diabetes, preference for fried or barbecued foods and polymorphism in the $A C E, A T R$, and CYP11B2 genes of the RAAS system were associated with elevated risk of hypertension among Hui Hajj pilgrims in Gansu Province, China. Lifestyle and genetic risks were independently associated with elevated risk of hypertension among those population.

Table 4 Genetic diversity of different mutation sites

\begin{tabular}{lllllll}
\hline Gene & Loci & He & Ho & Ne & PIC & $P$ value $^{*}$ \\
\hline ACE & rs4425 & 0.669 & 0.331 & 1.429 & 0.389 & 1.18 \\
& rs4429 & 0.697 & 0.303 & 1.435 & 0.368 & 5.57 \\
& rs4337 & 0.647 & 0.352 & 1.546 & 0.379 & 4.65 \\
ATR & rs129876 & 0.846 & 0.154 & 1.182 & 0.370 & 3.60 \\
AGT & rs3637 & 0.823 & 0.177 & 1.215 & 0.378 & 1.79 \\
CYP11B2 & rs1912 & 0.829 & 0.171 & 1.206 & 0.331 & 4.05
\end{tabular}

Note. He means Heterozygosity. Ho means Homozygosity. Ne means Effective allele. PIC refers to the value of a marker used to detect polymorphisms in a population. PIC depends on the number of alleles detected and their frequency distribution. The value is equal to 1 minus the sum of the squared frequencies of all alleles. PIC $>0.5$ means high diversity, $0.25<\mathrm{PIC}<0.5$ means moderate diversity, $\mathrm{PIC}<0.25$ means low diversity. ${ }^{*}$ The results from the Chi Square Test

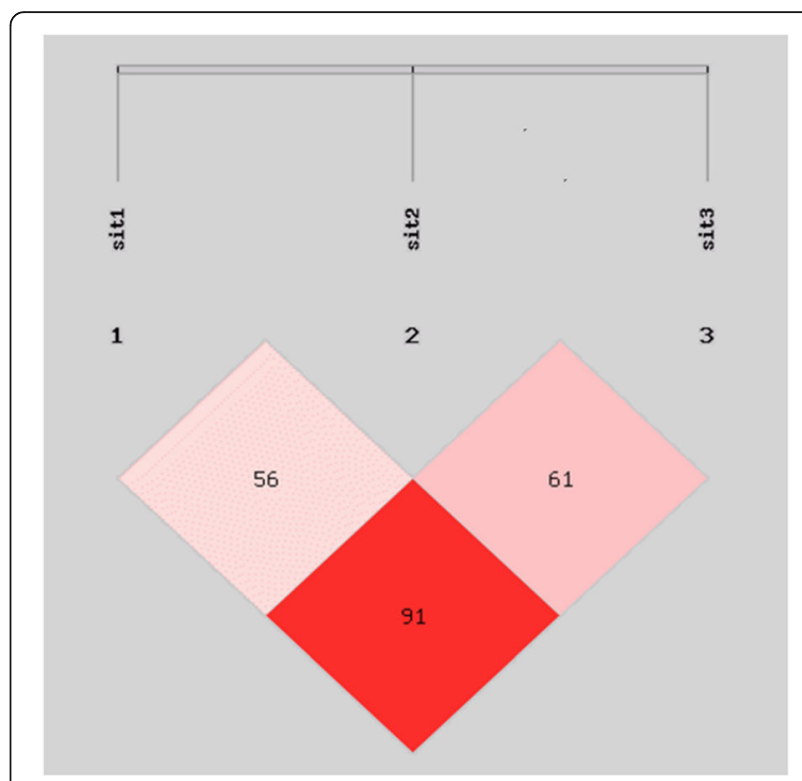

Fig. 3 The linkage disequilibrium patterns of ACE polymorphisms

In present study, those pilgrims are relatively older and more likely to be overweight or obese than average populations $[24,25]$. What's more, the prevalence of hypertension of the pilgrims is higher than other populations, which are consistent with previous reports [26, 27]. Therefore, the health management departments should pay more attention to chronic disease in particular hypertension among Chinese Hajj pilgrims. Several studies have shown a close relationship between hypertension and diabetes. The prevalence of hypertension in diabetics is about twice that in non-diabetics, what's more striking, the prevalence peaks 10 years earlier in diabetic groups. That implicates that even individuals with the same genotype may show different phenotypic traits when exposed to different environmental factors. In our study, the prevalence of hypertension family history is similar between the hypertension and normal groups, which reflects the fact that the measurement error could not be ruled out, as the participants are older and less well educated, thus unaware or unconcerned about their parents' and grandparents' health.

Our results were also consistent with previous studies, which showed that population with high prevalence of hypertension was more likely to engage in poor dietary behaviors, especially eating fried or barbecued foods. Frying or barbecuing food involves a large amount of fat, and adding excess salt. Elevated cholesterol levels can directly damage the vascular endothelium and increase blood pressure. Sodium is an independent risk factor for heart disease and stroke [28]. Previous research revealed a Ushaped relationship between sodium intake and hypertension, which indicated both low and high sodium intake were associated with increased rates of hypertension [29]. 


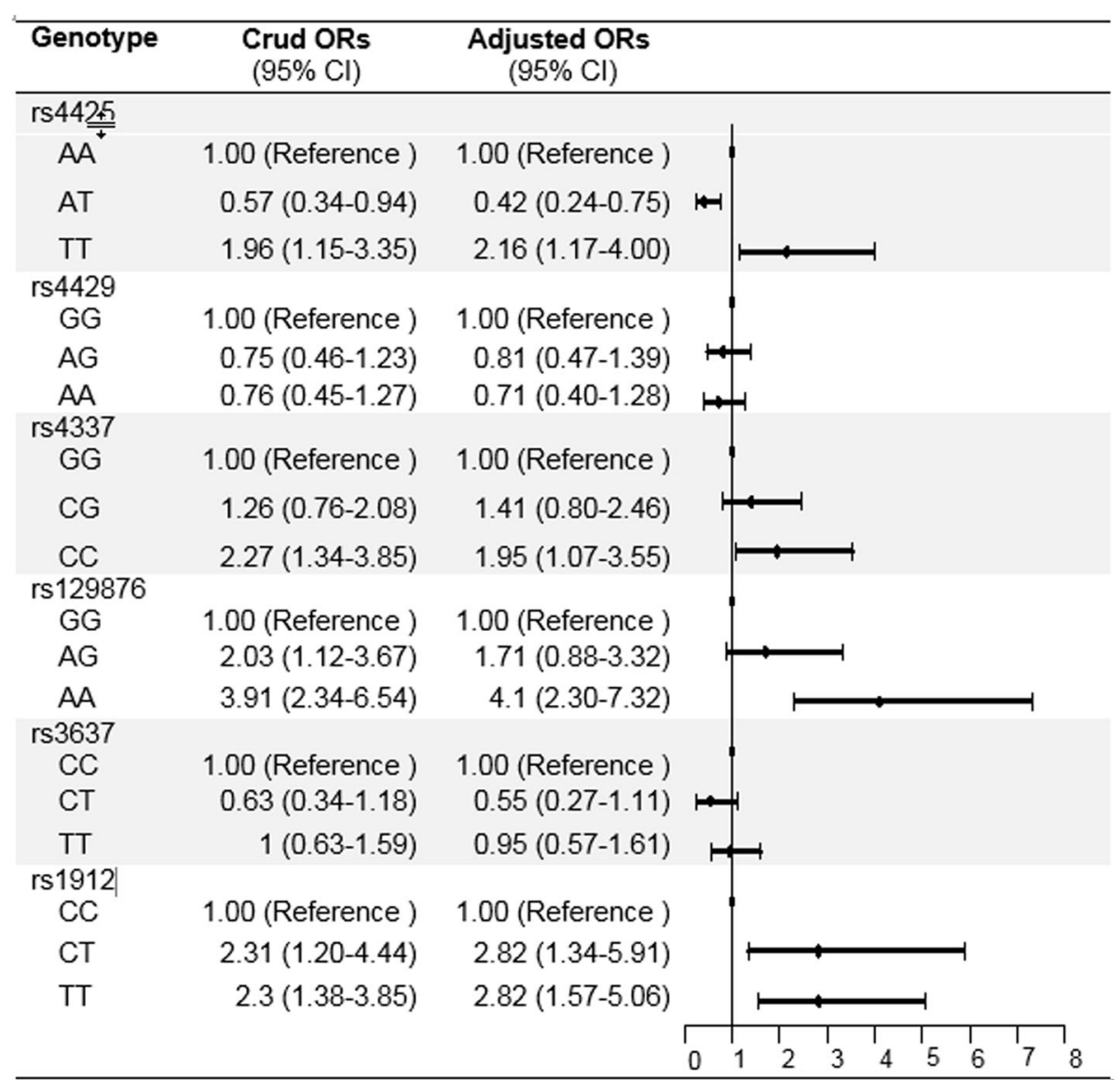

Fig. 4 Associations between genotypes and risk of hypertension in Chinese pilgrims to Hajj. The dots and horizontal lines are ORs and 95\% confidence intervals (Cls) using multivariate logistic regression analysis after adjustment for: age, sex, marital status, monthly family income, BMI, tobacco smoking, alcohol drinking, physical activity, diabetes and family history of hypertension

The strength of the association between sodium intake and hypertension also rises with age [30, 31]. Worship frequency was the main form of daily exercise for those pilgrims, however, it is not related with the risk of hypertension in this study. Therefore, it is suggested that improving the dietary habits of Hui Muslims should be a key strategy in basic public health services and the management of basic public health services. We should adjust the allocation of resources and devote more resources to health education so as to effectively influence and improve of the dietary habits of Muslims, which will increase the control rate of hypertension while reduce the morbidity and the possibility of various complications among Hui people.

Many studies have found that more than 220 loci are closely related to hypertension, and variants of these loci can affect blood pressure levels and increase the risk of hypertension [32]. RAAS is a hormone system that regulates blood pressure and fluid balance, which plays a very important role in blood pressure regulation. In this study population, the statistically significant difference between participants with and without hypertension in the following RAAS sites: rs4425 and rs4337 in the ACE gene, rs29876 in the ATR gene and rs1912 in the CYP11B2 gene. These potentially hypertension-associated polymorphisms differ from those reported in other studies on Chinese and nonChinese populations [33, 34]. This discrepancy is consistent with a literature showing different genetic risk factors for hypertension depending on time period, geographic region and ethnicity $[1,10]$. Genome-wide association studies are needed to clarify these discrepancies, which help us gain a more complete understanding of the genetic risk factors for hypertension. ACE rs4425, ACE rs4337, ART rs 129876 and CYP11B2 rs1912 polymorphism were associated with an increased risk of hypertension in mutant homozygous genotype. It is advised that consideration be given to striving for conditions to carry out the related gene detection work and genome-wide association studies in a planned and step-by-step way among the Hui people in Gansu Province or in some key areas. The targeted and effective 
prevention and treatment strategies of hypertension can be adopted to reduce the economic cost of related diseases and improve the output/input ratio. Moving toward precision medicine will have positive sociological and health economics implications.

This finding reflected the potential positive relationship between the $R A A S$ system and salt-sensitive hypertension $[35,36]$. For example, expression of ATR can increase renal transport or vascular smooth muscle cell reactivity, while $A C E$ helps metabolize vasoactive peptides. $A G T$ is associated with a reduction in blood pressure after salt intake $[3,37]$. Salt intake may affect the $R A A S$ system to a greater extent in older people, whose blood pressure is extremely sensitive to salt intake [38]. Behavior often determines whether or not people are exposed to environmental risk factors and the degree of exposure. Therefore, the interaction between genes and environment based on behavior research is conducive to further clarifying the pathogenesis of hypertension, and the intervention of behavioral factors with high variability is easy to be realized, providing ideas for the effective prevention and treatment of hypertension. While the cross-sectional nature of this study prevents us from exploring causal relationships between behavioral and genetic factors and hypertension, our results provide testable hypotheses for future prospective studies.

Several strengths and limitations need to be kept in mind when interpreting these findings. First, studies on lifestyle and genetic risks in Chinese pilgrims are very limited, we comprehensively examined the factors associated with hypertension and their interactions with potential genetic factors among Hui Hajj pilgrims in China. Second, comprehensive information regarding potential confounders was also carefully measured and analyzed, thus minimizing the probability of bias. Third, we further evaluated the interactions between lifestyle and genetic factors with risk of hypertension. The main limitation of this study is its cross-sectional nature, causality cannot be established. Another limitation is some common risk factors for hypertension such as raised non-HDL cholesterol and chronic kidney disease were not included in this study. Additionally, we did not to distinguish participants who are newly diagnosed with their clinical examination, and those who are known to have a clinically diagnosed hypertension prior to their participation in this study that would lead to a biased conclusion.

\section{Conclusion}

In summary, this study observed that lifestyle and genetic risks were independently associated with hypertension risk Hui pilgrims in China. Identifying individuals who are at high risk of hypertension is helpful in providing them an efficient means of prevention, further longitudinal studies and serum levels of components testing are warranted to replicate this finding.

\section{Additional file}

Additional file 1: Supplemental Tables. (DOCX 19 kb)

\begin{abstract}
Abbreviations
ACE: Angiotensin converting enzyme; AGT: Angiotensinogen; Ang: Angiotensin; ATR: Angiotensin II receptor; BMl: Body mass index; CVD: Cardiovascular disease; CYP11B2: Aldosterone synthase; DBP: Diastolic blood pressure; DNA: Deoxyribonucleic acid; FPG: Fasting plasma glucose; He: Heterozygosity; Ho: Homozygosity; Ne: Effective number of allele gene; PCR: Polymerase Chain Reaction; PIC: Polymorphism Information Content; RAAS: Renin-angiotensin-aldosterone system; SBP: Systolic blood pressure; WHO: World Health Organization
\end{abstract}

\section{Acknowledgements}

We all thank all study participants and the staff of the Gansu International Travel Healthcare Center, as well as Northwest Minzu University and Gansu agricultural university. The authors would like to acknowledge their field work and contribution.

\section{Authors' contributions}

YZ and AY performed the data analyses and wrote the manuscript; BZ and $X M$ initiated the study design and helped with implementation; FS conducted data analysis and editing manuscript. ZY, MZ, JW and HY helped perform the analysis with constructive discussions. All authors have read and approved the final manuscript.

\section{Funding}

This work is supported by the Special Funds for Basic Scientific Research Operations of Central Universities (31920170044), which provides guidance for the design and implementation of the project. The authors are solely responsible for the content of this paper.

\section{Availability of data and materials}

Original data of this study will not be shared because it is part of health examination data and blood samples of the Gansu International Travel Healthcare Center.

\section{Ethics approval and consent to participate}

The study protocol was approved by the Medical Research Ethics Committee of the Northwestern Minzu University, and all participants provided written informed consent.

\section{Consent for publication}

Not applicable.

\section{Competing interests}

The authors declare that they have no competing interests.

\section{Author details}

${ }^{1}$ West China School of Public Health and West China Fourth Hospital, Sichuan University, Chengdu 610000, China. ${ }^{2}$ Northwest Minzu University, Lanzhou 730030, China. ${ }^{3}$ Center for Disease Control and Prevention, Kongtong District, Pingliang, Gansu, China. ${ }^{4}$ Qingyang People's Hospital, Qingyang 745000, China. ${ }^{5}$ Hong Kong Institute of Diabetes and Obesity, The Chinese University of Hong Kong, Kowloon, Hong Kong SAR. ${ }^{6}$ Gansu International Travel Healthcare Center, Lanzhou 730000, China. ${ }^{7}$ School of Public Health, Lanzhou University, Lanzhou 730000, China.

Received: 7 March 2019 Accepted: 22 July 2019

Published online: 04 September 2019

\section{References}

1. Padmanabhan S, Caulfield M, Dominiczak AF. Genetic and molecular aspects of hypertension. Circ Res. 2015;116:937-59. 
2. Lynch Al, Tang W, Shi G, Devereux RB, et al. Epistatic effects of ACE I/D and AGT gene variants on left ventricular mass in hypertensive patients, the HyperGEN study. J Hum Hypertens. 2012;26:133-40.

3. Gu D, Kelly TN, Hixson JE, et al. Genetic variants in the renin-angiotensinaldosterone system and salt sensitivity of blood pressure. J Hypertens. 2010; 28:1210-20.

4. Rapsomaniki E, Timmis A, George J, et al. Blood pressure and incidence of twelve cardiovascular diseases, lifetime risks, healthy life-years lost, and agespecific associations in 1.25 million people. Lancet. 2014;383:1899-911.

5. Kearney PM, Whelton M, Reynolds K, et al. Global burden of hypertension: analysis of worldwide data. Lancet. 2005;365:217-23.

6. Al Shimemeri A. Cardiovascular disease in Hajj pilgrims. I Saudi Heart Assoc. 2012;24:123-7.

7. Shafi S, Dar O, Khan $\mathrm{M}$, et al. The annual hajj pilgrimage-minimizing the risk of ill health in pilgrims from Europe and opportunity for driving the best prevention and health promotion guidelines. Int J Infect Dis. 2016;47:79-82.

8. Memish ZA, Zumla A, Alhakeem RF, et al. Hajj, infectious disease surveillance and control. Lancet. 2014;383:2073-82.

9. Mills KT, Bundy JD, Kelly TN, et al. Global disparities of hypertension prevalence and control, a systematic analysis of population-based studies from 90 countries. Circulation. 2016;134:441-50.

10. Lu X, Wang L, Lin X, et al. Genome-wide association study in Chinese identifies novel loci for blood pressure and hypertension. Hum Mol Genet. 2015;24:865-74.

11. Savoia C, Volpe M. Angiotensin receptor modulation and cardiovascular remodeling. J Renin-Angiotensin-Aldosterone SystJRAAS. 2011;12:381-4.

12. Horiuchi M, Iwanami J, Mogi M. Regulation of angiotensin II receptors beyond the classical pathway. Clin Sci. 2012;123:193-203.

13. Tang WR, Wu HY, Zhou XH, et al. Association of the C-344T polymorphism of CYP11B2 gene with essential hypertension in Hani and Yi minorities of China. Clin Chim Acta. 2006:364(1-2):222-5.

14. Chan Q, Stamler J, Griep LMO, et al. An update on nutrients and blood pressure summary of INTERMAP study findings. J Atheroscler Thromb. 2016;23:276-89.

15. Yu G, Fu H, Huang W, et al. A dietary pattern of higher fish, egg, Milk, nut, vegetable and fruit and lower salt intake correlates with the prevalence and control of hypertension. Am J Hypertens. 2018;31(6):679-86,

16. Lelong H, Galan P, Kesse-Guyot E, et al. Relationship between nutrition and blood pressure, a cross-sectional analysis from the NutriNet-Sante study, a French web-based cohort study. Am J Hypertens. 2015;28:362-71.

17. Mang X. The Wugong of Islam and the Women's health of the hui nationality. J Yunnan Univ Natl. 2001;18:54-7 (In Chinese).

18. Wei L. The prevalence of hypertension in pilgrims in Gansu and its relationship with blood cell parameters. Chin J Dis Control Prev. 2013;17: 118-21 (In Chinese).

19. Leung AA, Daskalopoulou SS, Dasgupta K, et al. Hypertension Canada's 2017 guidelines for diagnosis, risk assessment, prevention, and treatment of hypertension in adults. Can J Cardiol. 2017;33:557-76.

20. Chalmers J, MacMahon S, Mancia G, et al. World Health OrganizationInternational Society of Hypertension Guidelines for the Management of Hypertension [J]. J Hypertens. 1999, 17(2):151-83.

21. Anasagasti A, Barandika O, Irigoyen C, et al. Genetic high throughput screening in retinitis pigmentosa based on high resolution melting (HRM) analysis. Exp Eye Res. 2013;116:386-94.

22. Kommoju UJ, Maruda J, Kadarkarai Samy S, et al. Association of IRS1, CAPN10, and PPARG gene polymorphisms with type 2 diabetes mellitus in the high-risk population of Hyderabad, India. J Diabetes. 2014;6:564-73.

23. Gundry CN, Dobrowolski SF, Martin YR, et al. Base-pair neutral homozygotes can be discriminated by calibrated high-resolution melting of small amplicons. Nucleic Acids Res. 2008;36:3401-8.

24. Gautret P, Bauge M, Simon F, et al. Overweight and obesity in French hajj pilgrims. J Immigr Minor Health. 2013;15:215-8.

25. Memish ZA, Stephens GM, Steffen R, Ahmed QA. Emergence of medicine for mass gatherings, lessons from the hajj. Lancet Infect Dis. 2012;12:56-65.

26. Gautret P, Yong W, Soula G, et al. Incidence of hajj-associated febrile cough episodes among French pilgrims, a prospective cohort study on the influence of statin use and risk factors. Clin Microbiol Infect, off publ Eur Soc Clin Microbiol Infect Dis. 2009;15:335-40.

27. Gautret P, Soula G, Delmont J, Parola P, Brouqui P. Common health hazards in French pilgrims during the hajj of 2007, a prospective cohort study. J Travel Med. 2009;16:377-81.
28. Whelton PK, Appel L, Sacco RL, et al. Sodium, blood pressure, and cardiovascular disease, further evidence supporting the American Heart Association sodium reduction recommendations. Circulation. 2012;126:2880-9.

29. Graudal N, Jurgens G, Baslund B, Alderman MH. Compared with usual sodium intake, low- and excessive-sodium diets are associated with increased mortality, a meta-analysis. Am J Hypertens. 2014;27:1 129-37.

30. Mente A, O'Donnell MJ, Rangarajan S, et al. Association of urinary sodium and potassium excretion with blood pressure. N Engl J Med. 2014;371:601-11.

31. Takase H, Sugiura T, Kimura G, Ohte N, Dohi Y. Dietary sodium consumption predicts future blood pressure and incident hypertension in the Japanese normotensive general population. J Am Heart Assoc. 2015:4:e001959.

32. Ren M, Ng FL, Warren HR, et al. The biological impact of blood pressureassociated genetic variants in the natriuretic peptide receptor $\mathrm{C}$ gene on human vascular smooth muscle [J]. Hum Mol Genet. 2018;27(1):199-210.

33. Levy D, Ehret GB, Rice K, et al. Genome-wide association study of blood pressure and hypertension. Nat Genet. 2009;41:677-87.

34. Niu W, Qi Y. Association of the angiotensin II type I receptor gene +1166 a $>$ C polymorphism with hypertension risk, evidence from a meta-analysis of 16474 participants. Hypertens res, off J Jpn Soc Hypertens. 2010;33:1137-43.

35. Hasimu B, Nakayama T, Mizutani Y, et al. Haplotype analysis of the human renin gene and Essential hypertension. Hypertension. 2002;41:308-12.

36. Sanada H, Jones JE, Jose PA. Genetics of salt-sensitive hypertension. Curr Hypertens Rep. 2011;13:55-66.

37. Strazzullo P, Galletti F. Genetics of salt-sensitive hypertension. Curr Hypertens Rep. 2007;9:25-32.

38. Cogswell ME, Zhang Z, Carriquiry AL, et al. Sodium and potassium intakes among US adults, NHANES 2003-2008. Am J Clin Nutr. 2012;96:647-57.

\section{Publisher's Note}

Springer Nature remains neutral with regard to jurisdictional claims in published maps and institutional affiliations.

Ready to submit your research? Choose BMC and benefit from:

- fast, convenient online submission

- thorough peer review by experienced researchers in your field

- rapid publication on acceptance

- support for research data, including large and complex data types

- gold Open Access which fosters wider collaboration and increased citations

- maximum visibility for your research: over $100 \mathrm{M}$ website views per year

At $\mathrm{BMC}$, research is always in progress.

Learn more biomedcentral.com/submissions 